\title{
The 10th International Conference on Life Cycle Management 2021-Stuttgart, Germany, September 05-08, 2021
}

\author{
Matthias Fischer ${ }^{1}$ (1) $\cdot$ Mercedes Barkmeyer ${ }^{2} \cdot$ Stefan Albrecht $^{1} \cdot$ Anna Braune $^{3} \cdot$ Philip Leistner $^{4} \cdot$ Rainer Seifert $^{2}$. \\ Johannes Kreissig ${ }^{3}$
}

Received: 22 February 2021 / Accepted: 24 February 2021 / Published online: 16 March 2021

(c) The Author(s) 2021

\section{Invitation}

Fraunhofer Institute for Building Physics, University of Stuttgart, German Sustainable Building Council DGNB, and Festo SE \& Co. KG invite you to participate in the 10th Conference on Life Cycle Management "Building a Sustainable Future Based on Innovation and Digitalization (LCM 2021)" on September 05-08, 2021.

For the 10th anniversary event of the conference series, we are again expecting more than 700 participants from about 40 countries, as was the case for the past events in Poznań (2019), Luxembourg (2017), and Bordeaux (2015), to discuss the current questions connected with life cycle management (LCM). The conference will be organized in Stuttgart, Germany, but given the current boundary conditions, the conference will be held as an online event. The strong industrial region of Stuttgart, known for its hidden champions, small and medium enterprises, global acting corporations, and leading research institutions and universities, will be present in the digital world, and we invite all of you to join this first online LCM conference. We would like to use this unique opportunity to implement our

Communicated by Matthias Finkbeiner.

Conference Website: www.lcm2021.org

Matthias Fischer

matthias.fischer@ibp.fraunhofer.de

1 Department Life Cycle Engineering GaBi, Fraunhofer Institute for Building Physics IBP, Wankelstr. 5, 70563 Stuttgart, Germany

2 Festo SE \& Co. KG, Corporate Responsibility, Esslingen, Germany

3 German Sustainable Building Council DGNB, Stuttgart, Germany

4 Institute for Acoustics and Building Physics IABP, University of Stuttgart, Stuttgart, Germany conference motto "Building a Sustainable Future Based on Innovation and Digitalization" in the digital world and invite not only well-known and experienced LCM participants but also new ones from all regions of the world. Be part of LCM, shape the future by sustainability, and join this online conference.

\section{Theme}

The LCM conference series is one of the world's leading forums for environmental, economic, and social sustainability. The focus is on practical solutions for the implementation of life cycle approaches into strategic and operational decision-making, whether in science, industry, NGOs, or public institutions. With a research institution, a university, an industry network, and an industry partner, we have four hosts covering LCM topics from basic and applied research to industrial and political implementation. Along the life cycle, all industry sectors and supply chain stages, company sizes, sustainability focuses, research activities, and stakeholders are invited to contribute. Challenges and solutions will be discussed, and fruitful collaboration will be strengthened in networking opportunities.

In the call for abstracts, authors are invited to submit their contribution under one of the following topics:

\subsection{Building a sustainable future facing the climate challenge}

1. Life cycle and circular economy

1.1. Circular economy buildings-from research to practice

1.2. Tools, metrics, and labels for a circular economy

1.3. Life cycle approaches in the raw materials sector 
2. Urban living and mobility

2.1. Transformation towards future mobility

2.2. Decarbonized mobility along the value chain

2.3. Future sustainable lifestyles - urban structure and individual choices

3. Sustainability and impact assessment

3.1. Life cycle sustainability in construction and renovation of buildings

3.2. Achieving sustainability goals on the regional, national, and international levels

3.3. Land use and biodiversity in life cycle management

3.4. Addressing marine litter within life cycle assessment and management

3.5. Carbon inventory and management of bio-based materials for a post-fossil bioeconomy

3.6. SDG as a basis for sustainability assessments of products and companies

3.7. Operationalizing life cycle sustainability assessment

\subsection{Innovation-a key driver for more sustainability}

4. Life cycle and circular economy in innovation

4.1. Methodological approaches to assess life cycle consequences

4.2. Prospective life cycle sustainability assessment of energy technologies

4.3. Benefits of retaining materials and their quality in a circular economy

4.4. Circularity and life cycle aspects of recycling technologies

5. Application and transfer to business

5.1. Life cycle innovation to drive sustainability and business performance

5.2. Sustainability of business models and innovations

5.3. Transfer towards climate neutrality—scenarios, options, and valuation

5.4. Business models for a circular economy

5.5. Business life cycle networks

5.6. Life cycle thinking in companies and organizations

5.7. Sustainability assessments in industry creating meaningful information

5.8. Developing sustainable chemicals and materials based on innovation and digitalization

6. Life cycle impacts, metrics, and data in innovation
6.1. Life cycle metrics in sustainable finance

6.2. Social life cycle assessment of products

6.3. What gets measured, gets improved-impact assessment and environmental labeling along the production chain

\subsection{Digitalization-digital solutions for industry and society}

7. Digitalization in circular economy

7.1. Digital technologies for a circular economy

7.2. Circular economy and circular society in LCM

8. Digital solutions for life cycle management

8.1. Green-lean-digital

8.2. Mainstreaming construction LCA-based on an open data network

8.3. Mobilizing LCA resources through digital collaboration

8.4. Applied digital solutions-connecting green and digital transformations?

8.5. Building information modeling (BIM) and life cycle assessment

8.6. Life cycle data supporting supply chain management and procurement

9. LCM and digitalization

9.1. Life cycle management in education and capacity building

9.2. The role of industry in sustainable supply chains

Additional spaces for networking, individual discussions, and group discussions will be arranged in online mode.

"Building a Sustainable Future Based on Innovation and Digitalization" is our motto, our claim, and our vision.

\section{Important dates and deadlines}

The most important dates of the conference are the following:

- A call for abstracts: till March 31, 2021.

- A call for early bird registration: till May 31, 2021.

- A call for registration: till July 15, 2021.

- A call for late registration: till August 15, 2021.

For further information, visit the conference website www. 1cm2021.org or contact contact@1cm2021.org.

See you online at the beginning of September 2021. 
Funding Open Access funding enabled and organized by Projekt DEAL.

Open Access This article is licensed under a Creative Commons Attribution 4.0 International License, which permits use, sharing, adaptation, distribution and reproduction in any medium or format, as long as you give appropriate credit to the original author(s) and the source, provide a link to the Creative Commons licence, and indicate if changes were made. The images or other third party material in this article are included in the article's Creative Commons licence, unless indicated otherwise in a credit line to the material. If material is not included in the article's Creative Commons licence and your intended use is not permitted by statutory regulation or exceeds the permitted use, you will need to obtain permission directly from the copyright holder. To view a copy of this licence, visit http://creativecommons.org/licenses/by/4.0/. 